\title{
Thermochemical Assessment of Solid and Liquid Fuels Used for Domestic Space Heating in Jordan
}

\author{
Khalid M. Tawarah \\ Department of Chemistry, Yarmouk University, Irbid, Jordan \\ Email: khalidtawarah@hotmail.com
}

Received 3 September 2014; revised 29 September 2014; accepted 25 October 2014

Copyright (C) 2014 by author and Scientific Research Publishing Inc.

This work is licensed under the Creative Commons Attribution International License (CC BY).

http://creativecommons.org/licenses/by/4.0/

(c) (i) Open Access

\section{Abstract}

The gross calorific values of crude and exhausted olive pomace, oak, almond, olive wood, olive oil, kerosene, and diesel are reported in this article. Conversion of crude olive pomace into exhausted olive pomace resulted in $\mathbf{1 0 \%}$ reduction in calorific value. The net calorific value of crude olive pomace amounts to $92 \%$ of its gross calorific value. The ultimate and proximate analyses of crude olive pomace representing the 2006-2008 olive harvest seasons were determined and compared with analyses pertaining to the 2009-2011 olive harvest seasons in Jordan. Controlled charring of crude olive pomace reduced its mass down to about $20 \%$. Pyrolysis thermogravimetric (TG) and differential thermogravimetric (DTG) curves were recorded under nitrogen atmosphere for crude olive pomace and wood samples. Quantitative data on three DTG major peaks are reported for wood samples and crude olive pomace. A comparison based on market price and calorific value of a fuel showed that olive pomace is the most rewarding fuel for domestic space heating in Jordan.

\section{Keywords}

Olive Pomace, Fire Wood, Kerosene, Diesel, Gross Calorific Value, Net Calorific Value, Biomass, Charring

\section{Introduction}

The olive pomace is the solid byproduct that results from the olive oil industry. Until very recently, the accumulation of olive pomace in the premises of the olive mills in Jordan constituted a very heavy burden on the environment due to the lack of large-scale useful uses for such material. However, since the turn of the twenty-first century, the olive pomace in Jordan has become a precious asset for olive mills owners due to the heavy demand 
on its use as a solid fuel useful for heat generation during winter time especially in residential space heating. Unlike exhausted olive pomace, which is practically oil-free pomace, the olive pomace in Jordan is a crude pomace that retains its residual oil. The available statistics on olive pomace production in Jordan over the period 2000-2008 [1] indicate that the annual production fluctuates between a minimum of about 25,000 metric ton in 2001 and a maximum of about 50,000 metric ton in 2006. However, the current amounts of sun-dried crude olive pomace are expected to be much larger than the ones included in this statistics because of the growing interest in planting olives in Jordan. The relevant literature information concerning olive pomace in Jordan has focused on its co-firing with liquid diesel fuel in a slurry form [2], exploring briquettes of olive pomace as a potential source of thermal energy [3], drying characteristics [4], characterization of activated carbon produced from olive pomace [5], use of partially pyrolyzed olive pomace as sorbent for preconcentration of environmental waters [6], and characterization of crude and exhausted olive pomace [7].

The aim of the present work is to provide thermochemical data for the local liquid and solid fuels, namely: kerosene, diesel, local fire wood and olive pomace which represent the types of fuels used for space heating in Jordan. Such data can be combined with fuel price and availability to assess its suitability for domestic space heating.

\section{Materials and Experimental Procedures}

A brief description of the samples used in the present study is given in Table 1. All the reported measurements concerning the wood and pomace samples were carried out on powder samples. A hand-held drill was used to get samples from the wood chunks; further grinding was achieved by using a laboratory grinder. The bark of wood samples was excluded. The grinder was also used for preparing the powder of the olive pomace samples. Care was taken to avoid formation of oil droplets due to heat generated during the grinding step of the pomace samples. The liquid samples of olive oil, kerosene, and diesel were used as received. The sulfur and nitrogen content of these liquid samples was determined by X-ray fluorescence. The nitrogen content of the wood and olive pomace samples was estimated from the acid wash at the end of the oxygen bomb calorimetric measurement. $\mathrm{NaOH}$ with molarity of $0.0866 \mathrm{M}$ was used for titrating the acid wash with phenolphthalein as indicator. The moisture content of the solid samples was determined by drying at $110^{\circ} \mathrm{C}$ for about 15 hours in a conventional drying oven. The ash content of the solid samples was determined by burning the test sample in a muffle furnace at $600^{\circ} \mathrm{C}$ for three hours. The reported results of moisture and ash content are averages of two runs. Percentages of carbon and hydrogen of wood and olive pomace were determined by using an elemental analyzer. The thermogravimetric analysis of the wood and olive pomace samples was carried out by using a TGA-50 Shimadzu Thermogravimetric Analyzer stationed at the Research Laboratories Division, Jordan University of Science and Technology (JUST). The pyrolysis thermograms were recorded under the following conditions: An inert atmosphere of nitrogen at a flow rate of $50 \mathrm{ml}$ per min, a heating rate of $25^{\circ} \mathrm{C}$ per min from room temperature up to about $600^{\circ} \mathrm{C}$, and the use of aluminum crucibles with pierced lids. The heat of combustion (gross calorific value, GCV) measurements were carried out by using an adiabatic oxygen bomb calorimeter (IKA C 2000 Calorimeter System) stationed at the Royal Scientific Society (RSS). The reported data of the GCV are averages of two runs.

The sieving experiment, which aimed at finding the particle size distribution of the as-received loose sundried olive pomace sample, was carried out by using a set of ASTM standard sieves and a laboratory shaker. Five sieves with mesh designations of 10, 18, 35, 60, and 100 were used. Sample KT26, with initial mass of 2.5 $\mathrm{kg}$, is the source of the pomace material used in the sieving experiment. Prior to sieving, several batches of the sample have their lumps crushed for one min. The cumulative mass of the ground batches is $533.6 \mathrm{~g}$ which amounts to $21.3 \%$ of the original sample mass. In order to find the mass percentage of the sieved fractions, the amount of pomace powder retained by each one of the five sieves was weighed. The mass of the fine powder that passed through the 100-mesh sieve was also determined.

Charring of crude olive pomace was carried out on samples KT25 and KT26 which represent sun-dried compact fire logs and loose olive pomace, respectively. About one kg of each sample was charred in a grill placed in an outdoor environment. Few sprays of kerosene were used to start the charring process and every care was taken to avoid ash formation. The char yield of sample KT25 is $20.71 \%$, and that of sample KT26 is $21.32 \%$. About $11 \%$ of the char of these two samples was used for ash determination. Twelve replicates of ash determinations were carried out for each one of these two samples. 
Table 1. Brief description of olive pomace, fire wood, and liquid samples used in the present study.

\begin{tabular}{|c|c|c|c|c|}
\hline Sample identity & Acquisition time & Sample physical state & Sample source & Remarks \\
\hline KT7 & October 2006 & Slurry & a'Sa'doon new olive mill & $\begin{array}{l}\text { Virgin pomace collected from } \\
\text { mill operation line }\end{array}$ \\
\hline KT8 & September 2007 & Wood chunks & Al-Huson wood shop & Oak wood, bark neglected \\
\hline KT9 & September 2007 & Wood chunks & Al-Huson wood shop & Almond wood, bark neglected \\
\hline KT12 & May 2006 & Briquettes & 'Sa'doon old mill & $\begin{array}{l}\text { Pomace collected from mill } \\
\text { drying yard }\end{array}$ \\
\hline KT13 & December 2006 & Briquettes & Pomace shop (Amman) & $\begin{array}{l}\text { Sample of pomace used for } \\
\text { solid-fired residential boiler }\end{array}$ \\
\hline KT14 & October 2007 & Wood chunks & Al-Huson wood shop & Olive wood, bark neglected \\
\hline KT23 & May 2008 & Dry olive pulp & Sa'doon old mill & Pulp of KT25 \\
\hline KT24 & May 2008 & Dry olive pits & Sa'doon old mill & Pits of KT25 \\
\hline KT25 & May 2008 & Briquettes & Sa'doon old mill & $\begin{array}{l}\text { Pomace collected from mill } \\
\text { drying yard }\end{array}$ \\
\hline KT26 & June 2008 & Loose pomace & Sa'doon old mill & $\begin{array}{l}\text { Pomace collected from mill } \\
\text { drying yard }\end{array}$ \\
\hline KT27 & June 2008 & Powder of KT26 & Sa'doon old mill & Mesh: +10 \\
\hline KT28 & June 2008 & Powder of KT26 & Sa'doon old mill & Mesh: $-10,+18$ \\
\hline KT29 & June 2008 & Powder of KT26 & Sa'doon old mill & Mesh: $-18,+35$ \\
\hline КT30 & June 2008 & Powder of KT26 & Sa'doon old mill & Mesh: $-35,+60$ \\
\hline КT31 & June 2008 & Powder of KT26 & Sa'doon old mill & Mesh: $-60,+100$ \\
\hline KT32 & June 2008 & Powder of KT26 & Sa'doon old mill & Mesh: -100 \\
\hline КT33 & December 2008 & Liquid olive oil & $\begin{array}{l}\text { Al-Kfarat, Irbid } \\
\text { Governorate }\end{array}$ & Extra virgin olive oil \\
\hline КT34 & May 2009 & Liquid kerosene & Gas station, Irbid & Local grade \\
\hline KT35 & May 2009 & Liquid diesel & Gas station, Amman & Local grade \\
\hline
\end{tabular}

a,b: Two neighboring olive mills located near Al-Nuaymeh intersection, Amman-Irbid highway.

The exhausted olive pomace samples were prepared from the crude olive pomace samples, namely: KT7, KT12, KT13, KT25, KT26, KT27, and KT32. Extraction of the fat material present in the crude olive pomace was achieved by using n-hexane with purity of $95 \%$. A Soxhlet extractor and cellulose extraction thimbles were used in the extraction experiments. About five grams of the test sample and $200 \mathrm{ml}$ of hexane were used in each extraction experiment. Exhaustive extraction lasted for about 48 hours. In naming the extractives-free residue, the letter "h" is added as a suffix to the symbol of the crude pomace sample used in the hexane extraction experiment.

\section{Results and Discussions}

\subsection{Fluctuations in Olive Pomace Production}

The olive tree exhibits an alternate bearing phenomenon (biennial bearing cycle) where the amount of the annual yield for two successive years is quite different. Consequently, fluctuations in the amount of the olive mill solid residue occur for a certain period of time. Figure 1 shows a graph of such fluctuations in the period 2000-2008 olive harvest seasons in Jordan. The graph is based on numerical data given as part of an annual agricultural statistics report [1]. The fluctuations in the annual yield of olive pomace have serious consequences on the end users who buy olive pomace for space heating in winter times. 


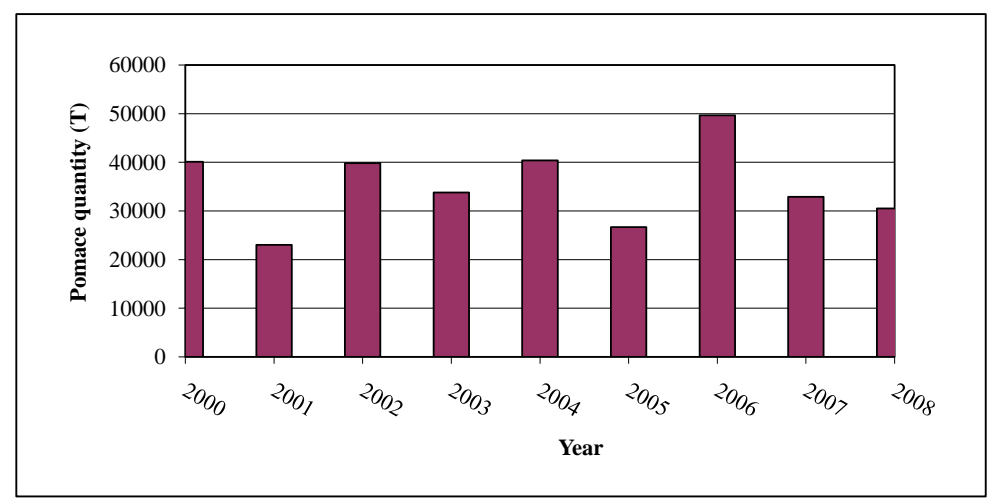

Figure 1. A bar graph of the annual production of sun-dried crude olive pomace in Jordan in the period 2000-2008.

\subsection{Moisture and Ash Content}

\subsubsection{Moisture Content}

The results of moisture content are given in Table 2. All of the samples have moisture content less than 10\%. The differences in the moisture content among the samples reflect variations in sample history. With the exception of sample KT7 which received special treatment of not being exposed to direct sun light, the moisture content of KT26 and its sieved fractions seems to be higher than that of the other olive pomace samples. Samples KT26-KT32 had not been stored for long and presumably contained appreciable volatile matter to be lost in the moisture determination experiments. Being the one with smallest particle size, sample KT32 is a fine powder which is expected to have the highest surface area. Fine powder samples usually retain much water and other volatiles which necessarily lead to higher moisture loss upon heating.

\subsubsection{Ashe Content}

Examination of the ash percentages given in Table 2 indicates that the percentages fall in the range $0.5 \%$ to $6 \%$. It should be mentioned that samples KT23 and KT24 are hand-separated pulp and pits fractions of a batch of sample KT25 with mass proportions equal to 55\% pulp and $45 \%$ crushed pits. Based on this information and the ash percentages of samples KT23 and KT24, the calculated ash percentage of sample KT25 is $3.081 \%$ which is less than the actual value by $7.6 \%$. Within the limits of experimental error, this result is an indication of selfconsistency in the results of these three samples. However, such self-consistency was not observed for sample KT26 and its sieved fractions given in Section 3.2.3; presumably due to the fact that each sieved fraction is a mix of variable proportions of both pits and pulp fractions. The gradual increase in the ash content as the particle size diminishes is quite evident in Table 2 for the sieved fractions. Based on differences in physical hardness of pits and pulp, it is quite reasonable to assume that samples KT27, KT28, and KT29 are fractions rich in mill-crushed pits. The average ash\% of these three samples is $1.064 \%$, which is close to the ash\% of the pure pits of sample KT24. On the other hand, samples KT30, KT31, and KT32 can be assumed to be rich in crushed pulp. Among these samples, sample KT32 with ash\% equal to 88\% of that of the pure pulp of sample KT23 seems to be the fraction with highest pulp content. The ash content of the pit sample reported in the present study falls in a literature range of $0.35 \%-1.55 \%$ [8]. As with regard to the other pomace samples, we note that samples KT25 and KT26 have nearly the same history and their ash percentages are within $\pm 3.2 \%$ from their average. Sample KT7, which is a virgin olive pomace, gave the lowest \% ash among the non-fractioned pomace samples. This sample was air-dried at home for few months; then drying was completed for one year in the laboratory environment. The \% ash of this sample is very close to that of several pomace samples representing the 2010 and 2011 harvest seasons in Jordan [7]. The remaining samples, KT12 and KT13, were obtained from different locations in the same harvest season; sample KT13 gave \% ash close to that of samples KT25 and KT26 while the ash \% of sample KT12 is within the range of ash percentages of samples taken in the 2010 and 2011 olive harvest seasons [7]. The ash content of the wood samples given in the present study is lower than those given in the literature, especially the almond and olive wood samples. For pellets of almond, holm oak, and olive trees, the literature values are $3.5 \%, 4.5 \%$, and $5.9 \%$, respectively [9]. 
Table 2. Moisture and ash content of olive pomace and fire wood samples.

\begin{tabular}{cccccc}
\hline Sample & Moisture $\%$ & Ash \% & Sample & Moisture \% & Ash \% \\
\hline KT7 & 6.775 & 2.215 & KT25 & 5.965 & 3.335 \\
KT8 & 5.601 & 5.882 & KT26 & 7.298 & 3.558 \\
KT9 & 4.865 & 0.628 & KT27 & 6.940 & 0.757 \\
KT12 & 5.351 & 5.397 & KT28 & 6.921 & 0.835 \\
KT13 & 5.250 & 3.282 & KT29 & 7.118 & 1.600 \\
KT14 & 4.806 & 0.577 & KT30 & 7.807 & 3.500 \\
KT23 & 5.662 & 4.613 & KT31 & 6.570 & 3.680 \\
KT24 & 5.811 & 1.208 & KT32 & 8.745 & 4.056 \\
\hline
\end{tabular}

\subsubsection{Distribution of Particle Size of Sun-Dried Crude Olive Pomace}

The distribution of particle size of an olive mill solid waste is governed by several factors. These factors include the type of olive mill, the mill operational parameters, the size distribution of the olive drupes, and the pits/pulp ratio of ripe olives. Visual inspection of sun-dried olive pomace has shown appreciable amounts of tiny uncrushed pits. Relatively small olives have small pits that might escape crushing during the olive oil extraction stages. It is also known that olive mills generate sizable amounts of fine solids in their waste water. In this case the yield of marketable olive pomace may be reduced. For space heating purposes, marketable olive pomace is usually sold in the form of cylindrical pieces (fire logs) with mass of about $1 \mathrm{~kg}$ and a height of about $20 \mathrm{~cm}$. If the freshly prepared cylindrical pieces have high content of fine particles and moisture, they might develop cracks during their sun-drying stage due to excessive expulsion of moisture content. This is a disadvantage for the end user in terms of transportation and storage. Therefore, it is preferable to have a balance between coarse and fine portions in order to have manageable dry fire logs. Because of these remarks, frequent check on the olive mill operational adjustments has to be carried out during the olive harvest season which is stretched over a period of about 10 weeks, starting at middle of October and ending at the end of December of each year. The data shown in Table 3 are results of a sieve analysis of an olive mill-crushed sun-dried olive pomace (sample KT26). If we consider mesh No. 35 as the border line between the coarse and fine fractions of the test sample, we notice that these fractions are nearly close to a 1:1 ratio. The handling loss in the sieving experiment is $1.92 \%$.

\subsubsection{Charred Olive Pomace}

In essence, the charring of the olive pomace samples as we did it is a controlled burning of the volatiles accompanied by the escape of the sample moisture. By doing that, the mass of the olive pomace sample was reduced to about $20 \%$ of its initial value. The char of the test sample was then burned in a muffle furnace at $600^{\circ} \mathrm{C}$ for three hours and the mineral content is left as ash. A more rigorous two-step procedure for preparing a low temperature ash begins with a pyrolysis step carried out in a tube furnace at about $500^{\circ} \mathrm{C}$ followed by burning the char at about $350^{\circ} \mathrm{C}$ for several hours [10]. The results of ash percentages relative to char mass and relative to the initial mass of the pomace sample are given in Table 4 and Table 5 for samples KT25 and KT26, respectively. The relation defined by Equation (1) was used for calculating the values of the $\%$ ash relative to the initial mass of the pomace sample. The results are given in the last columns of Table 4 and Table 5 .

$$
\% \text { Ash in olive pomace }=(\% \text { Ash in char })\left(\frac{y}{100}\right)
$$

In Equation (1), $\mathrm{y}$ is the \% of char yield; $\mathrm{y}=20.71 \%$ for sample KT25 and $21.32 \%$ for sample KT26. By comparing the ash percentages given in Table 2, and the averages given at the bottom of the last columns of Table 4, and Table 5 on dry basis, we find differences of $0.12 \%$ and $0.10 \%$ from the mean for samples KT25 and KT26, respectively. This excellent agreement implies that the charring process was properly done. Knowing the char yield and the moisture percentage, we can estimate the \% of volatile matter (VM) for the tested samples as will be shown in a later section. For sample KT25 the values of the standard deviation (based on "N-1" aver- 
Table 3. Distribution of particle size of sun-dried crude olive pomace.

\begin{tabular}{|c|c|c|c|c|}
\hline Fraction identity & Mesh No. & Aperture/mm & Fraction mass/g & Fraction \% \\
\hline KT27 & 10 & 2 & 114.16 & 21.39 \\
\hline KT28 & 18 & 1 & 114.25 & 21.41 \\
\hline KT29 & 35 & 0.51 & 42.29 & 7.93 \\
\hline КТ30 & 60 & 0.25 & 90.64 & 16.99 \\
\hline КT31 & 100 & 0.15 & 83.41 & 15.63 \\
\hline KT32 & $<100$ & $<0.15$ & 78.59 & 14.73 \\
\hline Sum & & & 523.34 & $98.08 \%$ \\
\hline
\end{tabular}

Table 4. The ash content of crude olive pomace and char of sample KT25.

\begin{tabular}{ccccc}
\hline Trial No. & Char mass/g & Ash mass/g & \% of Char ash & \% of Pomace ash \\
\hline 1 & 2.1834 & 0.3357 & 15.3751 & 3.1842 \\
2 & 2.2452 & 0.3954 & 17.6109 & 3.6472 \\
3 & 2.5284 & 0.6050 & 23.9282 & 4.9555 \\
4 & 2.4900 & 0.4215 & 16.9277 & 3.5057 \\
5 & 2.3013 & 0.3791 & 16.4733 & 3.4116 \\
6 & 2.3816 & 0.3156 & 13.2516 & 2.7444 \\
7 & 2.3270 & 0.3664 & 15.7456 & 3.2609 \\
8 & 2.4923 & 0.4594 & 18.4328 & 3.8174 \\
9 & 2.2637 & 0.3603 & 15.9164 & 3.2963 \\
10 & 2.5009 & 0.3727 & 14.9026 & 3.0863 \\
11 & 2.2895 & 0.2807 & 12.2603 & 2.5391 \\
\hline 12 & 2.2320 & 0.2873 & 12.8719 & 2.6658 \\
\hline
\end{tabular}

Table 5. The ash content of crude olive pomace and char of sample KT26.

\begin{tabular}{|c|c|c|c|c|}
\hline Trial No. & Char mass/g & Ash mass/g & $\%$ of Char ash & $\%$ of Pomace ash \\
\hline 1 & 2.2054 & 0.3206 & 14.5370 & 3.0993 \\
\hline 2 & 2.2423 & 0.3073 & 13.7047 & 2.9218 \\
\hline 3 & 2.3886 & 0.5027 & 21.0458 & 4.4870 \\
\hline 4 & 2.0952 & 0.3757 & 17.9315 & 3.8230 \\
\hline 5 & 2.3317 & 0.4271 & 18.3171 & 3.9052 \\
\hline 6 & 2.4435 & 0.3451 & 14.1232 & 3.0111 \\
\hline 7 & 2.3700 & 0.4295 & 18.1224 & 3.8637 \\
\hline 8 & 2.3969 & 0.3774 & 15.7453 & 3.3569 \\
\hline 9 & 2.6724 & 0.5025 & 18.8033 & 4.0089 \\
\hline 10 & 2.2996 & 0.4228 & 18.3858 & 3.9199 \\
\hline 11 & 2.2188 & 0.4018 & 18.1089 & 3.8608 \\
\hline 12 & 2.2348 & 0.2649 & 11.8534 & 2.5271 \\
\hline Average ash \% & & & 16.7232 & 3.5654 \\
\hline
\end{tabular}


age), are: 3.092 for \% ash relative to char mass and 0.640 for $\%$ ash relative to pomace mass. The corresponding values for sample KT26 are 2.679 for \% ash relative to char mass and 0.571 for \% ash relative to pomace mass. The values of the percentage relative deviation, \% R.D (\% R.D = mean of absolute deviations $\times 100$ /average) are $13.1 \%$ and $13.6 \%$ for ash data given in Table 4 and Table 5 of samples KT25 and KT26, respectively.

\subsubsection{Proximate Analysis of Crude Olive Pomace}

Knowledge of the proximate analysis of a fuel is necessary for evaluating its potential for energy production. The proximate analysis is a list of the percentages of moisture, ash, fixed carbon (FC), and volatile matter. The non-automated ASTM method [11] is usually used for finding the percentages of fixed carbon and volatile matter. Nowadays, the TG technique is considered as a reliable and time-saving technique for finding proximate analysis [12]. In connection to this matter, a comparison of traditional ASTM methods and TG determined volatile matter and ash content of various animal manures has been reported [13]. In a previous publication [7], we reported the proximate analysis of several olive pomace samples (samples belong to the 2009-2011 olive harvest seasons in Jordan) based on locating certain temperatures and residual masses on the TG curve of the test sample. The proximate analysis data obtained by this procedure were tested by a correlation formula suggested by Parikh et al. [14]. The formula predicts the higher heat value (HHV, HHV = GCV) of a fuel from its proximate analysis. The calculated GCV values were found to be in excellent agreement with the values obtained calorimetrically. For comparison purposes, we have calculated average proximate analysis for the previously reported results [7]. The calculated averages are: $\%$ ash $=5.2, \% \mathrm{FC}=25.8$ and $\% \mathrm{VM}=69.9 \%$. In the present study we have chosen a procedure for deriving the percentages of fixed carbon and volatile matter from char-based data of samples KT25 and KT26. In this case the mass of the char is assumed to be the sum of the masses of fixed carbon and ash, while the mass loss accompanying the char formation is assumed to be the sum of the masses of volatile matter and the sample moisture. Based on these assumptions we calculated the proximate analysis of samples KT25 and KT26 as given in Table 6. Comparison on dry basis of the average proximate analysis given in this table with the above mentioned average proximate analysis of the data reported previously [7] indicated that the differences in percentages as reported in the present study are: \% VM is 7.6 percentage points higher while the \% FC and \% ash are 7 and 1.5 percentage points lower, respectively. From other literature data related to the present study, we cite: (a) \% VM of 80.94, 79.10, 77.77; \% FC of 18.50, 15.30, 17.92; \% ash of 0.56, 5.6, and 4.31 on dry basis for pits, pulp, and residue of olive pomace, respectively [15]; (b) \% VM of 76.3\%, \% FC of $19.2 \%$, and $\%$ ash of $4.5 \%$ for olive pomace [16]; (c) \% VM of $86.51 \%$, $\%$ FC of $10.7 \%$, and $\%$ ash of $2.76 \%$ for olive pomace briquettes [3]. With the exception of the data reported in ref. [3], our results are in good agreement with the other cited literature data.

\subsubsection{Ultimate Analysis of Crude Olive Pomace}

The results of the ultimate analysis of crude olive pomace are given in Table 7 . The real crude olive pomace samples in this table are KT7, KT12, KT25, and KT26. Their average ultimate analysis is given as follows: \% ash $=3.868, \% \mathrm{C}=54.792, \% \mathrm{H}=7.605, \% \mathrm{~N}=0.788$ and $\% \mathrm{O}=32.948$. Certain observations can be pointed out from the data given in this table. For example samples having the same history such as KT25 and KT26, have nearly the same ultimate analysis while fractions of the same olive pomace such as the pairs KT23/KT24 and KT27/KT32 have significant differences in the contents of their mineral and nitrogen-containing compounds. Being pulp/or pulp rich, samples KT23 and KT32 indicate that the nitrogen-containing compounds and the minerals are largely contained in the pulp fraction of the olive pomace. The elemental analysis of an olive pomace sample taken from Ajloun Governorate (northern part of Jordan) has shown that the $\mathrm{C}, \mathrm{H}$, and $\mathrm{N}$ contents are $54.4 \%, 7.7 \%$, and $0.90 \%$, respectively [6]. These percentages are comparable with our data given in Table 7 .

Table 6. Proximate analysis of some crude olive pomace samples. Percentages of ash, fixed carbon, and volatile matter are given on dry basis.

\begin{tabular}{cccccc}
\hline Sample identity & \% Moisture & \% Ash & \% FC & \% VM & 77.976 \\
KT25 & 5.965 & 3.555 & 18.469 & 19.153 & 77.002 \\
KT26 & 7.298 & 3.846 & 18.811 & 77.489 \\
Average & - & 3.701 & 0.25 & \\
\hline
\end{tabular}


An attempt was made for comparing the proximate and ultimate analyses reported in the present study with their counterparts reported previously [7]. The results of this comparison are given in Table 8. Set 1 represents the present study while Set 2 represents the previous study. For proximate analysis, Set 1 is based on two samples, namely: KT25 and KT26 whose R.D value for \% ash is 3.9\% on dry basis. On the other hand Set 2 is based on six samples two of them have ash \% nearly 4 times the average of the other four samples. Set 2 has \% R.D of $6.6 \%$ for ash content. As with regard to ultimate analysis, Set 1 has four samples (fraction samples in Table 7 are excluded) while Set 2 has six samples. With the exception of \% R.D of the volatile matter, large deviations exist in the other values of the proximate analysis. In the case of ultimate analysis, there are also large deviations in the \% R.D values of ash and nitrogen. A reasonable explanation for the variations in the proximate and ultimate analyses of the two data sets can be presented on the basis of the fact that the data were collected over a period of six harvest seasons (2006-2011). Fluctuations in rain fall, inconsistent procedures in collecting and drying of olive pomace on the premises of olive mills, differences in olive cultivar and age of olive trees, and differences in the degree of ripeness of the olive fruits when brought to the olive mills are believed to be the cause of such variations. Despite all these remarks, the averages given in Table 8 can be used for specifications purposes of olive pomace in Jordan.

\subsubsection{Oxygen Bomb Calorimetric Measurements}

\section{1) The Gross and Net Calorific Values of Crude Olive Pomace and Its Fractions}

Table 7. Ultimate analysis of olive pomace and its fractions on dry basis.

\begin{tabular}{cccccc}
\hline Sample identity & \% Ash & \% C & \% H & \% N & a O \\
\hline KT7 & 2.38 & 53.89 & 7.40 & 0.63 & 35.70 \\
KT12 & 5.70 & 55.02 & 7.62 & 0.62 & 31.04 \\
KT25 & 3.55 & 55.13 & 7.70 & 0.97 & 32.65 \\
KT26 & 3.84 & 55.13 & 7.70 & 0.93 & 32.40 \\
KT23 & 4.89 & 57.45 & 7.80 & 6.06 & 28.80 \\
KT24 & 1.28 & 51.30 & 6.88 & 0.80 & 39.74 \\
KT27 & 0.81 & 51.04 & 6.75 & 6.80 & 40.59 \\
KT32 & 4.45 & 51.14 & 6.90 & 1.39 & 36.12 \\
\hline
\end{tabular}

${ }^{\mathrm{a}}$ : \% Oxygen determined by difference.

Table 8. Comparison of proximate and ultimate analyses of olive pomace for two data sets.

\begin{tabular}{|c|c|c|c|c|c|}
\hline \multicolumn{6}{|c|}{ Comparison of proximate analyses } \\
\hline Data set & $\%$ Ash & $\% \mathrm{FC}$ & $\% \mathrm{VM}$ & FC/VM & - \\
\hline Set 1 & 3.701 & 18.811 & 77.489 & 0.25 & - \\
\hline Set 2 & 5.183 & 25.8 & 69.9 & 0.37 & - \\
\hline Two-set average & 4.442 & 22.306 & 73.694 & 0.31 & - \\
\hline \% R.D & 16.7 & 15.7 & 5.1 & 19.4 & - \\
\hline \multicolumn{6}{|c|}{ Comparison of ultimate analyses } \\
\hline Data set & $\%$ Ash & $\% \mathrm{C}$ & $\% \mathrm{H}$ & $\% \mathrm{~N}$ & $\% \mathrm{O}$ \\
\hline Set 1 & 3.868 & 54.792 & 7.605 & 0.788 & 32.948 \\
\hline Set 2 & 5.17 & 51.36 & 6.42 & 1.16 & 35.90 \\
\hline Two-set average & 4.52 & 53.08 & 7.01 & 0.97 & 34.42 \\
\hline \% R.D & 14.4 & 3.2 & 8.4 & 19.1 & 4.3 \\
\hline
\end{tabular}


When a sample of a fuel is burned in an oxygen bomb calorimeter, the resulting amount of heat energy is known as GCV. However, burning the fuel in an industrial or domestic facility generates a different amount of energy known as the net calorific value (NCV). The magnitude of NCV is generally less than that of GCV. This difference is due to the fact that certain chemical and physical processes that take place under the oxygen bomb conditions cannot proceed when the fuel is burned under normal conditions of real life applications. In the case of a solid biomass fuel, such as olive pomace, the major corrections needed for getting the NCV value from the GCV value are the heat resulting from condensation of water coming from sample moisture and oxidation of sample hydrogen. Other corrections involve the heat of hydration of acids such as $\mathrm{HNO}_{3}, \mathrm{H}_{2} \mathrm{SO}_{4}, \mathrm{HCl}$, and any heat resulting from possible interaction of water vapor with the remaining inorganic constituent of the biomass material.

In the case of acid correction, the current information regarding the thermochemical corrections for oxygen bomb calorimetry [17] [18] only the heat resulting from the combination of water vapor with $\mathrm{HNO}_{3}$ and $\mathrm{H}_{2} \mathrm{SO}_{4}$ can be accounted for. The corrections are 59.7 and $297.2 \mathrm{~kJ}$ per mole for $\mathrm{HNO}_{3}$ and $\mathrm{H}_{2} \mathrm{SO}_{4}$, respectively. In terms of \% N and \% S, the corrections become 42.6 and $92.7 \mathrm{~J}$ per gram of sample for each percentage point of $\mathrm{N}$ and S, respectively [7]. The corrections due to condensation of water vapor in the oxygen bomb enclosure are (2.442) (\% moisture/100) and (2.442) (\% H/100) (9.01) (1-\% moisture/100) kJ per gram of wet sample for sample contents of moisture and hydrogen, respectively [7]. The factor 2.442 is the heat of condensation of water vapor in units of $\mathrm{kJ}$ per gram of condensed water based on a value of $43.990 \mathrm{~kJ} / \mathrm{mol}$ of condensed water at $25^{\circ} \mathrm{C}$ [19]. Based on this information, the value of NCV can be calculated on dry basis in units of Joule per gram of dry sample according to the following equation:

$$
\mathrm{NCV}=\mathrm{GCV}-(2442)\left(\frac{\% \mathrm{H}}{100}\right)(9.01)+(92.7)(\% \mathrm{~S})+(42.6)(\% \mathrm{~N})
$$

The values of the GCV reported in the second column of Table 9 are the data obtained from the oxygen bomb calorimeter while the values of NCV given in the table were calculated according to Equation (2). On the average, NCV amounts to 92\% of GCV. Correction due to condensation of water resulting from oxidation of hydrogen amounts to $7 \%$ of GCV. The remaining $1 \%$ of GCV corrections is the sum of corrections due to the hydration of $\mathrm{HNO}_{3}$ and $\mathrm{H}_{2} \mathrm{SO}_{4}$ and any other unaccounted for corrections. We have neglected $\mathrm{H}_{2} \mathrm{SO}_{4}$ correction since the \% S is usually less than $0.1 \%$ [3] [20] and the correction is within the margin of uncertainty in the GCV measurements. The average value of GCV reported in Table 9 on dry basis is in fair agreement with literature values of 21.2 [7], 23 [3], $22.24 \mathrm{~kJ} / \mathrm{g}$ [20] and $22.63-22.92 \mathrm{~kJ} / \mathrm{g}$ [21]. The results of the GCV of the pomace fractions are given in Table 10. The variations in GCV reflect the fact that the samples have variable proportions of pits and pulp. It is quite reasonable to assume that samples rich in pulp have higher heating value because pulp is the part of the olive fruit where the residual oil exists. This explains the high GCV value of sample KT23 (pure pulp) compared with the low value of sample KT24 (pure pits). The same argument applies for samples KT27-KT32 where samples KT30-KT32 are believed to have higher pulp content compared with grainy KT27-KT29 samples. The value of GCV on dry basis of the pit sample (KT24) is within the range given in the literature, 19.9 - 21.1 [8]. The calculation procedure of NCV of the pomace fractions is the same as the one used for crude olive pomace samples. In addition to these calculations, we carried out a calculation check on the

Table 9. Gross and net calorific values of crude olive pomace.

\begin{tabular}{ccccc}
\hline Sample identity & $\begin{array}{c}\text { GCV }(\mathrm{kJ} / \mathrm{g}), \\
\text { wet basis }\end{array}$ & $\begin{array}{c}\text { GCV }(\mathrm{kJ} / \mathrm{g}), \\
\text { dry basis }\end{array}$ & $\begin{array}{c}\text { NCV }(\mathrm{kJ} / \mathrm{g}), \\
\text { dry basis }\end{array}$ & $\begin{array}{c}\text { NCV/GCV, } \\
\text { dry basis }\end{array}$ \\
\hline KT7 & 20.891 & 22.409 & 20.754 & 0.926 \\
KT12 & 20.548 & 21.709 & 20.007 & 0.922 \\
${ }^{\mathrm{a}}$ KT13 & 19.836 & 20.935 & 19.219 & 0.918 \\
KT25 & 21.589 & 22.959 & 21.223 & 0.924 \\
KT26 & 20.878 & 22.522 & 20.788 & 0.923 \\
Average & 20.748 & 22.107 & 20.398 & 0.923 \\
\hline
\end{tabular}

\footnotetext{
${ }^{\mathrm{a}}$ : \% $\mathrm{H}$ for this sample is taken as average \% H of samples KT7, KT12, KT25, and KT26.
} 
Table 10. Calorific values of sieve-fractions of crude olive pomace.

\begin{tabular}{ccccc}
\hline Sample identity & $\begin{array}{c}\text { GCV }(\mathrm{kJ} / \mathrm{g}), \\
\text { wet basis }\end{array}$ & $\begin{array}{c}\text { GCV }(\mathrm{kJ} / \mathrm{g}), \\
\text { dry basis }\end{array}$ & $\begin{array}{c}\text { NCV }(\mathrm{kJ} / \mathrm{g}), \\
\text { dry basis }\end{array}$ & $\begin{array}{c}\text { NCV/GCV, } \\
\text { dry basis }\end{array}$ \\
\hline KT23 & 23.368 & 24.771 & 23.013 & 0.924 \\
KT24 & 19.129 & 20.309 & 18.762 & 0.924 \\
KT27 & 18.832 & 20.236 & 18.717 & n.d \\
KT28 & 18.585 & 19.967 & n.d & n.d \\
KT29 & 20.226 & 21.776 & n.d & n.d \\
KT30 & 23.121 & 25.079 & n.d & n.d \\
KT31 & 22.451 & 24.030 & 24.0916 & .d \\
KT32 & 21.987 & & & 0.934 \\
\hline
\end{tabular}

n.d: not determined.

GCV of samples KT25 and KT26. In the case of sample KT25, we used GCV of KT23 and KT24 and the mass fractions of 0.45 for pits (sample KT24) and 0.55 for pulp (sample KT23). The calculated value of GCV of sample KT25 is $22.763 \mathrm{~kJ} / \mathrm{g}$ which amounts to $99.2 \%$ of the calorimetric result on dry basis. Likewise, by using the mass fractions of KT26 given in Table 3 and the GCV given in Table 10 for six fractions (samples KT27KT32), the calculated GCV of sample KT 26 is $21.896 \mathrm{~kJ} / \mathrm{g}$ on dry basis. This value is $97.2 \%$ of the calorimetrically obtained value given in Table 9. It should be mentioned that the sum of percentages in Table 3 is $98.08 \%$ and the remaining $1.92 \%$ is considered as handling loss during the sieving experiment. The average value of the NCV/GCV ratio in Table 10 is 0.93 which is practically the same as the average given in Table 9 . The calculations we made so far in this section imply that our calorimetric data have high level of precision and consistency.

\section{2) The Gross Calorific Values of Exhausted Olive Pomace}

The exhausted olive pomace samples that we prepared and studied in the present work are listed in the first column of Table 11. The first five samples (samples KT7h, KT12h, KT13h, KT25h, and KT26h) were prepared from their parent samples of crude olive pomace, while samples KT27h and KT32h are exhausted olive pomace fractions prepared from KT27 and KT32 which are fractions of the crude olive pomace of sample KT26. As a comment on the data given in Table 11, we notice that sample KT7 (collected from the olive mill operation line) has the highest \% extractives because it was not exposed to weather conditions as the other samples; therefore it retained an appreciable amount of residual olive oil and other volatiles that can be extracted by hexane. As a manifestation of this fact, KT7h (which is an extractives-free version of KT7) has the lowest GCV among the other non-fractioned samples. On classification basis, sample KT7 is a virgin pomace as contrasted to crude and exhausted olive pomce types. Samples KT27 and KT32 are fraction samples; the first is assumed to be rich in pits but lean in fat material while the second is assumed to be rich in pulp and rich in fatty matter. These considerations are in accord with \% extractives and GCV ratio shown in the last column of Table 11. Also, samples having the same \% extractives have nearly the same reduction in their GCV as indicated by samples KT13h and KT27h. In all cases the GCV of an exhausted pomace is less than the GCV of the parent sample as seen in the last column of Table 11. When samples KT7h, KT27h, and KT32h are excluded, the remaining samples in Table 11 represent realistic exhausted olive pomace samples originated from sun-dried crude olive pomace. In this case, the average GCV of the four exhausted olive pomace samples is $20.169 \mathrm{~kJ} / \mathrm{g}$. The corresponding literature values are 20.07 [7] and 19.596 [23] kJ/g. The ratios given in the last column of Table 11 indicate the extent by which the value of GCV of a crude pomace is lowered by hexane extraction. The acid correction presented as $\mathrm{HNO}_{3}$ correction in Table 11 was obtained from the number of moles of $\mathrm{NaOH}$ consumed in the titration of the acid wash obtained after the combustion of the sample in the oxygen bomb and the factor $42.6 \mathrm{~J}$ per gram sample per percentage point of nitrogen. $\mathrm{H}_{2} \mathrm{SO}_{4}$ correction was neglected due to the low sulfur content of olive pomace. The moisture correction was calculated according to the factor 2.442 (\% moisture/100) kJ per gram of wet sample. Correction due to condensation of water vapor resulting from oxidation of sample hydrogen was not calculated due to the unavailability of hydrogen analysis. The average value of the sum of $\mathrm{HNO}_{3}$ and moisture 
corrections for data given in Table 11 amounts to $0.8 \%$ of the GCV.

\section{3) The Gross Calorific Values of Local Fire Wood}

Table 12 shows the GCV of oak, almond, and olive wood usually used for domestic space heating in Jordan. The calculated values on dry basis are in reasonable agreement with literature values [9] given in the last column of Table 12. Although sources of wood are very limited in Jordan, local fire wood is still in use for fire places despite its high prices. As indicated in Table 9, Table 11, and Table 12, the values of GCV of wood samples are a little lower than those of crude and exhausted olive pomace. In terms of market prices in Jordan, wood is more expensive than olive pomace, especially oak wood. Co-firing of wood and crude olive pomace is becoming a routine practice for firing fire places in Jordan. In this case crude olive pomace is considered as a starter in the co-firing process in addition to its participation in heat generation.

Based on personal observations of the present author, most of the wood sold during the 2014 winter season has high moisture content especially olive wood and the assorted wood mixture of almond and other related wood types; this high moisture content caused difficulties in maintaining a stable combustion in a fire place even in the presence of olive pomace. It is clear that in the absence of official specifications for the use and trade of solid fuels in Jordan, there will be health and environmental hazards. On terms of abundance and availability in the market, local wood can be considered as a non-renewable biomass in Jordan because of the scarcity of forests. This fact is the reason for marketing fire wood with high moisture content; the demand is high in winter time but wood drying is practiced at the low level by most owners of wood shops.

\section{4) The Gross Calorific Values of Olive Oil and Local Liquid Fuels}

The traditional liquid fuels used for residential space heating in Jordan are kerosene and diesel. Despite the fact that their current prices are nearly four times the prices a decade ago, these two liquid fuels are still used for diesel-fired central heating boilers and kerosene-fired space heating stoves. They are included in the present study for the purpose of determining the GCV of non-renewable fossil fuels. Therefore, their thermal capacity can be compared with the thermal capacity of a renewable biomass fuel. Although olive oil is intended for human consumption, it is also included in the present study to represent a renewable liquid fatty material. The values of GCV for olive oil, kerosene, and diesel are reported in Table 13 along with some literature values for olive oil [24] and for kerosene and diesel [25]. The \% S and \% N were determined by X-ray fluorescence and were used to calculate the $\mathrm{H}_{2} \mathrm{SO}_{4}$ and $\mathrm{HNO}_{3}$ corrections. When the sum of these acid corrections is calculated as \% of GCV for each liquid, the results are $0.15 \%, 0.28 \%$, and $0.32 \%$ for olive oil, kerosene, and diesel, respectively.

Table 11. Calorimetric data for exhausted olive pomace.

\begin{tabular}{|c|c|c|c|c|c|c|c|}
\hline Sample No. & $\begin{array}{c}\% \\
\text { Extractives } \\
\text { a(d. b) }\end{array}$ & $\%$ Moisture & $\begin{array}{l}\text { GCV } \\
\text { (kJ/g), } \\
\text { b(w. b) }\end{array}$ & $\begin{array}{c}\text { GCV } \\
\text { (kJ/g), } \\
\text { (d. b) }\end{array}$ & $\begin{array}{c}\mathrm{HNO}_{3} \\
\text { Correction, } \\
\text { J/g (d. b) }\end{array}$ & $\begin{array}{c}\text { Moisture } \\
\text { Correction, } \\
\text { J/g }\end{array}$ & $\begin{array}{l}{ }^{\mathrm{c}} \mathrm{GCV}_{\text {exh }} / \\
{ }^{\mathrm{d}} \mathrm{GCV}_{\text {cr }} \\
\text { (d. b) }\end{array}$ \\
\hline KT7h & 24.5 & 7.108 & 17.063 & 18.369 & 55 & 174 & 0.82 \\
\hline KT12h & 10.5 & 4.426 & 19.098 & 19.982 & 27 & 108 & 0.92 \\
\hline KT13h & 7.9 & 4.248 & 19.261 & 20.116 & 42 & 104 & 0.96 \\
\hline KT25h & 14.5 & 4.507 & 19.623 & 20.549 & 41 & 110 & 0.90 \\
\hline KT26h & 9.8 & 7.825 & 18.462 & 20.029 & 40 & 191 & 0.89 \\
\hline KT27h & 8.0 & 2.974 & 19.017 & 19.600 & 33 & 73 & 0.97 \\
\hline KT32h & 22.3 & 3.036 & 18.784 & 19.372 & 45 & 74 & 0.80 \\
\hline
\end{tabular}

${ }^{\mathrm{a}}$ : Dry basis; ${ }^{\mathrm{b}}$ : Wet basis; ${ }^{\mathrm{c}}$ : $\mathrm{GCV}_{\mathrm{exh}}$ of exhausted pomace; ${ }^{\mathrm{d}}$ : $\mathrm{GCV}_{\mathrm{cr}}$ of crude pomace.

Table 12. Calorimetric data for local fire wood samples.

\begin{tabular}{cccc}
\hline Sample identity & \% Moisture & $\begin{array}{c}\text { GCV (kJ/g), } \\
\text { (wet basis) }\end{array}$ & $\begin{array}{c}\text { GCV (kJ/g), } \\
\text { (dry basis) }\end{array}$ \\
\hline KT8 & 5.601 & 16.952 & 17.958 \\
KT9 & 4.865 & 18.556 & 19.505 \\
KT14 & 4.806 & 18.230 & 19.150 \\
\hline
\end{tabular}


As mentioned earlier in the discussion, these acid corrections are quite insignificant when compared with corrections of water condensation.

With gross calorific values, on wet basis, of 20.748, 16.952, and $44.942 \mathrm{~kJ} / \mathrm{g}$ for crude olive pomace, oak wood, and diesel, a comparison based on fuel price and calorific value is given in Table 14. It is evident from the values given in the last column of the table that olive pomace is the right choice as a fuel for space heating purposes in Jordan. In addition to its low nitrogen and sulfur content, olive pomace is abundant, carbon neutral, and a valuable renewable energy source in Jordan. With all these facts, olive pomace in Jordan deserves greater attention from the government since it contributes significantly to the energy demand in winter time.

\subsubsection{Results of Thermogravimetric Measurements}

\section{1) TG and DTG Curves of Oak, Almond, and Olive Fire Wood Samples}

The TG pyrolysis curves of oak, almond, and olive wood samples are shown in Figure 2. According to this figure, the major mass loss takes place in the temperature range $200^{\circ} \mathrm{C}-425^{\circ} \mathrm{C}$. More quantitative information about the pyrolysis of these wood samples can be obtained from their DTG curves shown in Figure 3. There are three peaks in this figure that correspond, in principle, to several mass loss processes. The low temperature peak is explained to be a physical process involving evolution of sample moisture and other light volatiles with peak temperature of about $90^{\circ} \mathrm{C}$. The other two peaks that appear at higher temperatures are explained to be due to overlapping chemical processes involving fragmentation of lignocelluloses. The reported DTG curves of xylan (a substitute for hemicellulose in lignocellulosic studies), lignin, and cellulose [26] indicate that xylan and lignin start decomposition at temperatures lower than cellulose and decomposition of lignin extends over a wide range of temperature. Moreover, the reported DTG peak temperatures, at a heating rate of $20^{\circ} \mathrm{C} / \mathrm{min}$, of xylan, lignin, and cellulose are $298^{\circ} \mathrm{C}, 350^{\circ} \mathrm{C}, 350^{\circ} \mathrm{C}$, respectively. It has also been reported that the main degradation peak of all wood species is due to the decomposition of cellulose and the shoulder on its left is due to decomposition of hemicellulose [27] [28]. It is worth mentioning that the characteristics of a DTG peak depend on heating rate [29], an observation to be considered when comparing peak value and peak temperature.

Guided with this literature information, the data given in Table 15 were collected by careful analysis of the DTG curves of Figure 3. Among the three wood samples investigated in the present study, only oak wood showed a lignin hump at $525^{\circ} \mathrm{C}$. There are slight differences in wood pyrolysis characteristics. For example olive wood starts decomposition at $200^{\circ} \mathrm{C}$ while almond and oak start at $250^{\circ} \mathrm{C}$. It is also evident that almond has the lowest cellulose peak temperature while oak and olive has nearly the same peak temperature. As with regard to the rate of maximum mass loss, the three wood types have nearly the same values for cellulose decomposition and loss of water, but different values are observed for decomposition of hemicellulose. At the end of the TG run, the three wood samples have nearly the same residual mass fraction at $600^{\circ} \mathrm{C}$.

\section{2) TG and DTG Curves of Crude Olive Pomace Samples}

Table 13. Calorimetric data for olive oil, kerosene, and diesel.

\begin{tabular}{ccccccc}
\hline Sample identity & $\% \mathrm{~S}$ & $\% \mathrm{~N}$ & $\begin{array}{c}\mathrm{GCV} \\
\text { (kJ/g), } \\
\text { (wet basis) }\end{array}$ & $\begin{array}{c}\mathrm{H}_{2} \mathrm{SO}_{4} \\
\text { correction, J/g } \\
\text { (wet basis) }\end{array}$ & $\begin{array}{c}\mathrm{HNO}_{3} \text { correction, } \\
\mathrm{J} / \mathrm{g} \\
\text { (wet basis) }\end{array}$ & Literature GCV, kJ/g \\
\hline KT33 & 0.0251 & 1.352 & 39.838 & 2 & 58 & $39.675[24]$ \\
KT34 & 0.1703 & 2.622 & 46.143 & 16 & 112 & $46.20[25]$ \\
KT35 & 1.0168 & 1.143 & 44.942 & 94 & 49 & $44.80[25]$ \\
\hline
\end{tabular}

Table 14. Energy and price comparison of solid and liquid fuels.

\begin{tabular}{|c|c|c|c|c|}
\hline Fuel type & Reference mass/ton & ${ }^{\mathrm{a}}$ Cost $/ \$$ per ton & $\begin{array}{l}\text { Heat energy/ } \\
10^{10} \mathrm{~J} \text { per ton }\end{array}$ & $\mathrm{MJ} / \$$ \\
\hline Olive pomace & 1 & 170 & 2.075 & 122.1 \\
\hline Oak wood & 1 & 255 & 1.695 & 66.5 \\
\hline${ }^{\mathrm{b}}$ Diesel & 1 & 1170 & 4.494 & 38.4 \\
\hline
\end{tabular}

${ }^{\mathrm{a}}$ : USD; ${ }^{\mathrm{b}}$ : Price per metric ton was calculated from the price per liter and a density of $0.85 \mathrm{~g} / \mathrm{cm}^{3}$. 


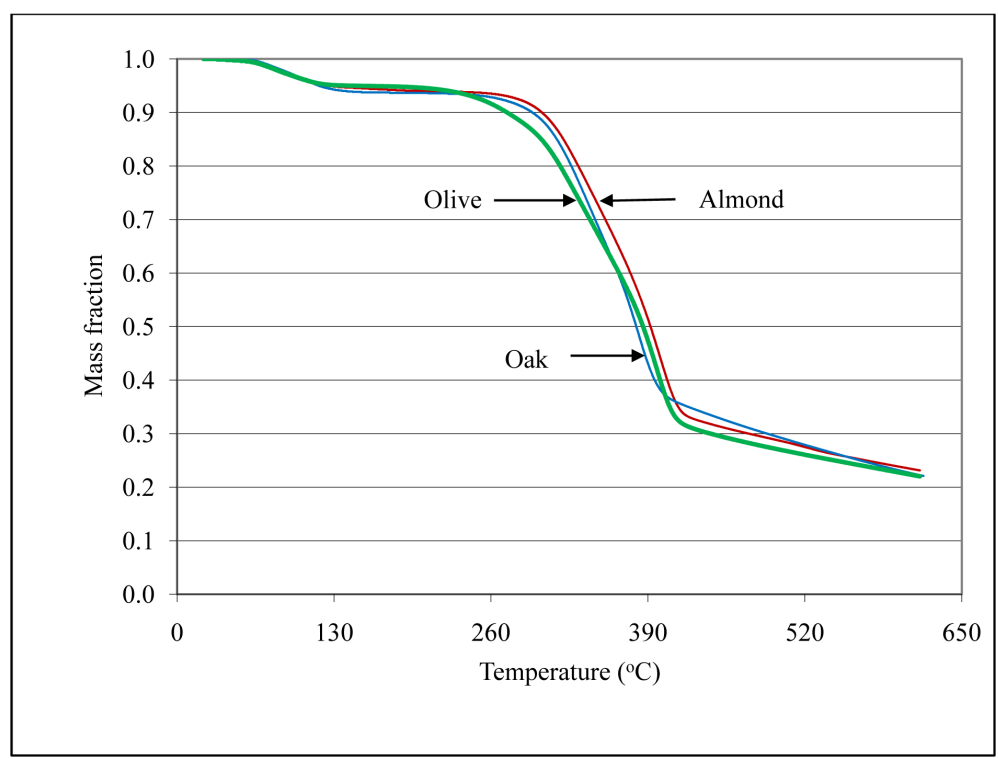

Figure 2. TG pyrolysis curves of oak, almond, and olive fire wood samples.

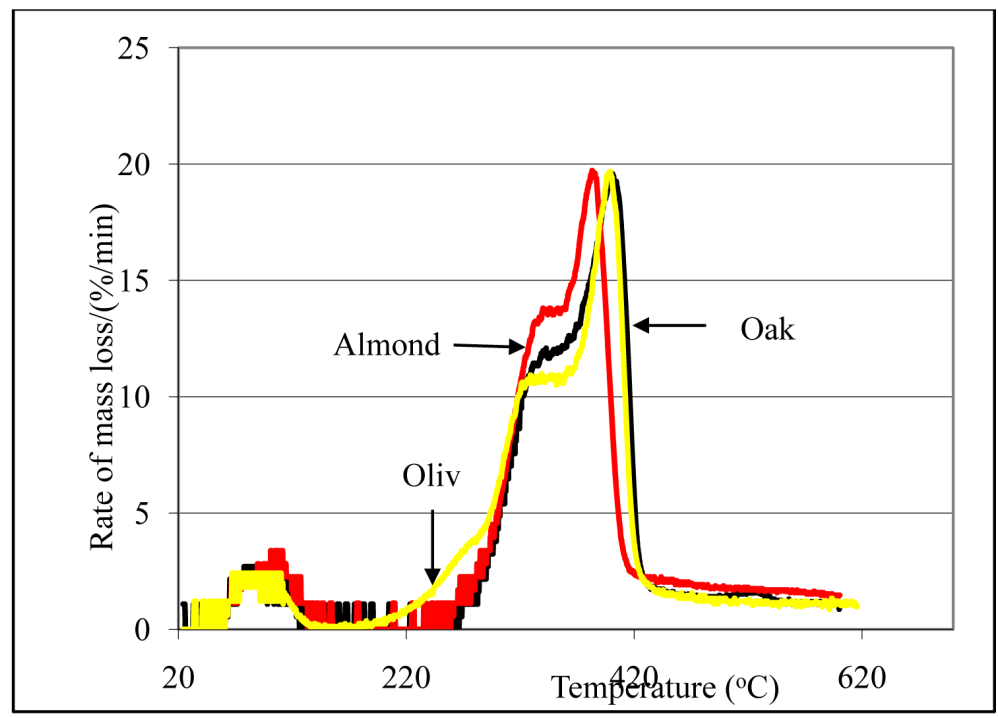

Figure 3. Plot of DTG curves of oak, almond, and olive fire wood samples.

The pyrolysis curves of three crude olive pomace samples are shown in Figure 4. Comparison of these TG curves with the TG curves of wood samples given in Figure 2 shows that the decomposition of the lignocellulosic matter of olive pomace starts and ends at temperatures lower than those of the wood samples. For olive pomace, major decomposition of its lignocelluloses takes place in the temperature range $180^{\circ} \mathrm{C}-400^{\circ} \mathrm{C}$. The TG curves depicted in Figure 4 show appreciable differences in the extent of lignocellulosic decomposition. These differences are also evident in the DTG curves in Figure 5. The same observations were noticed for samples KT23, KT24, KT25, KT27, and KT32. The DTG curves of sample KT25 and its pulp and pit fractions are given in Figure 6 while the DTG curves of samples KT27 and KT32 (sieve fractions of KT26) are given in Figure 7. In most cases, these DTG curves maintain the two-peak feature of the lignocelluloses decomposition of a biomass, which is largely attributed to hemicellulose/cellulose decomposition. However, lignin peaks were not detected except the high temperature humps in Figure 7. As with regard to peak value, all DTG curves shown in the present study have cellulose as the component with highest peak value; an exception is sample KT27 which has hemicellulose as the one with highest peak value. The DTG curves shown in Figure 6 indicate that the 


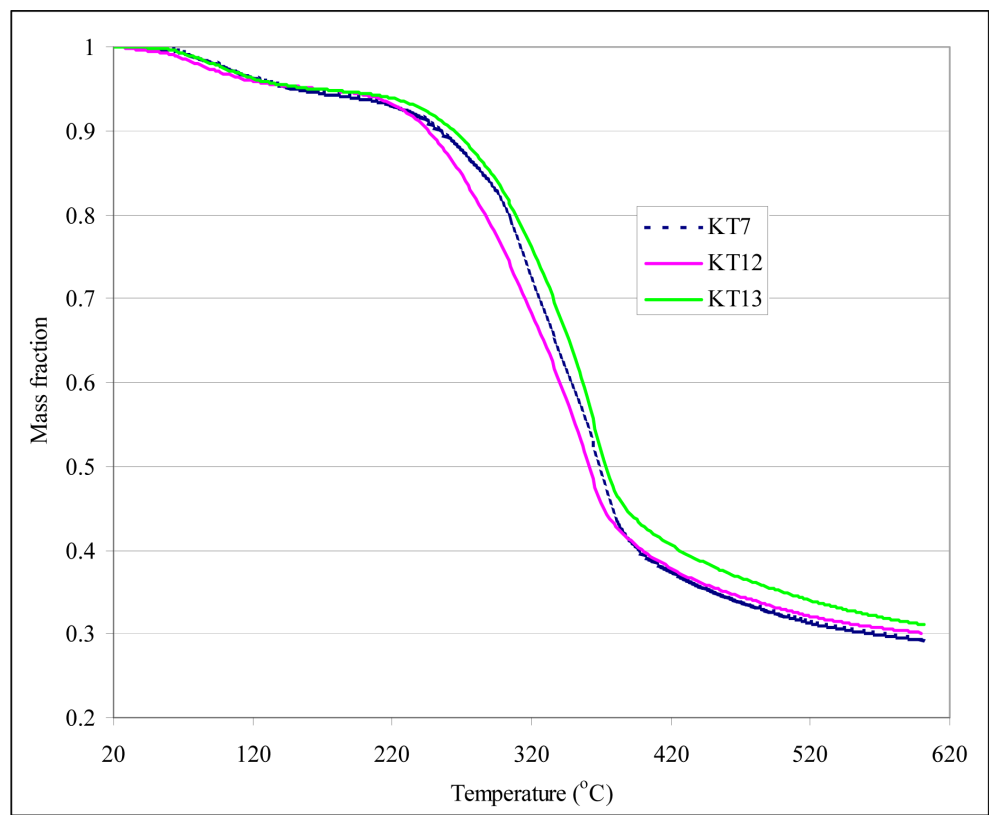

Figure 4. TG curves of crude olive pomace samples.

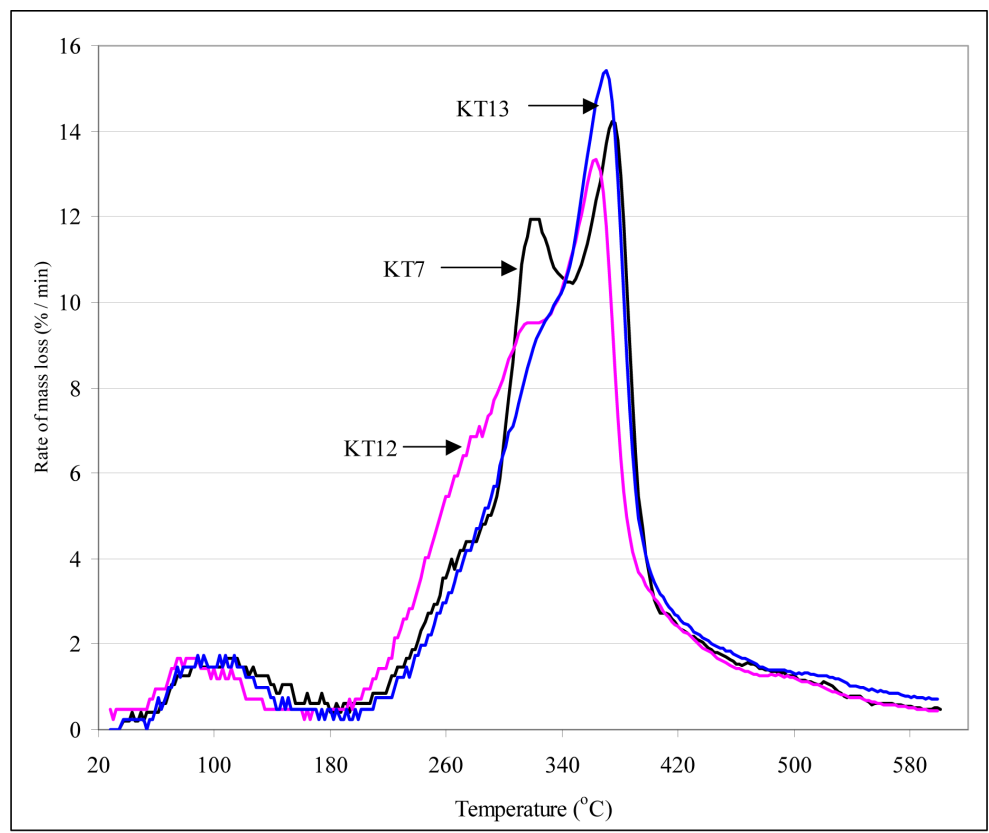

Figure 5. DTG curves of crude olive pomace samples.

maximum rates of mass loss for cellulose and hemicellulose are highest for pit fraction (sample KT24) and lowest for pulp fraction (sample KT23). The DTG curves shown in Figures 5-7 were analyzed to get quantitative information of the type given in Table 15. The results are collected in Table 16. It is seen in this table that samples KT23 (pulp of KT25) and KT32 (pulp-rich fraction of sample KT26) have hemicellulose peak temperatures appreciably lower than those of the other samples. In addition, the residual mass fraction given in the bottom row of Table 16 for sample KT32 seems unrealistic when compared with residual mass fractions of samples KT23 (pure pulp) and KT24 (pure pits). The cause of this result is very likely to be an equipment-related error such as a sudden high pulse of the flowing nitrogen gas. The detailed information given in Table 16 is transformed into concise form of ranges and averages as shown in Table 17. Whether we include or exclude sample 


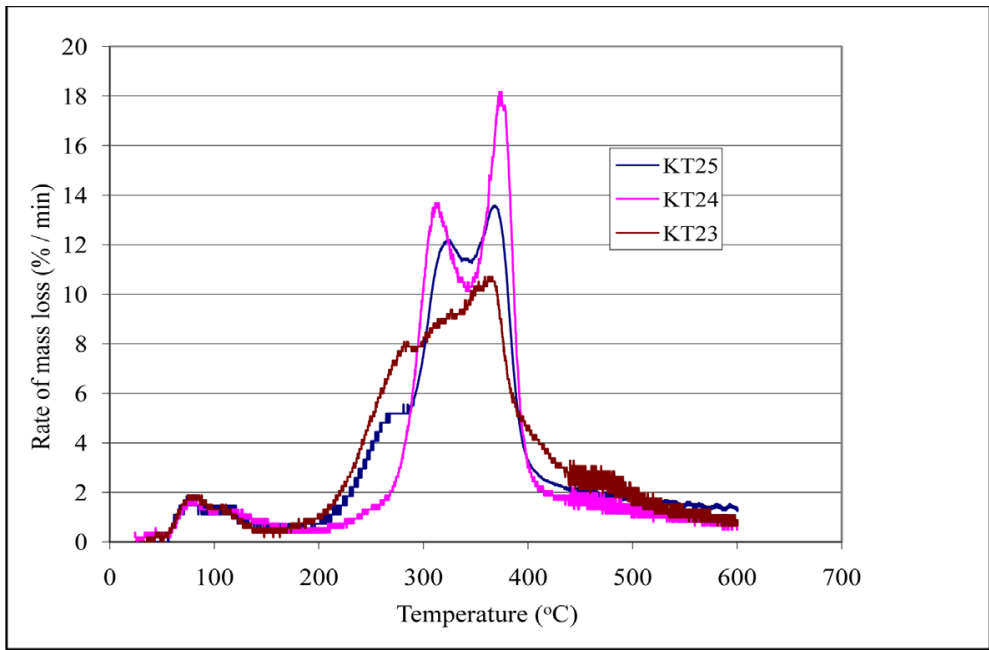

Figure 6. DTG plot of crude olive pomace and its pit and pulp fractions.

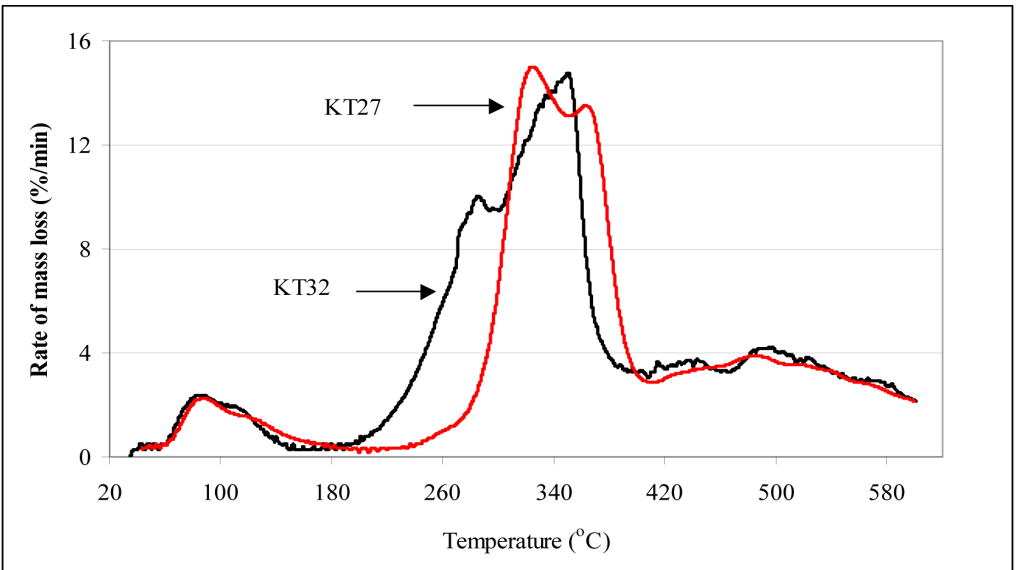

Figure 7. DTG plot of coarse and fine powder fractions of crude olive pomace.

Table 15. Maximum rate of mass loss and peak temperature of major derivatives on the DTG curves of oak, almond, and olive fire wood samples. Rates are given on dry basis.

\begin{tabular}{|c|c|c|c|}
\hline Sample identity & KT8 & KT9 & KT14 \\
\hline Sample mass (mg) & 11.78 & 13.43 & 10.44 \\
\hline Sample moisture (\%) & 5.60 & 4.86 & 4.81 \\
\hline Moisture peak temperature $\left({ }^{\circ} \mathrm{C}\right)$ & 90 & 93 & 90 \\
\hline Moisture maximum rate of mass loss $(\% / \mathrm{min})$ & 2.2 & 2.5 & 2.4 \\
\hline Hemicellulose peak temperature $\left({ }^{\circ} \mathrm{C}\right)$ & 342 & 342 & 340 \\
\hline Hemicellulose maximum rate of mass loss $(\% / \mathrm{min})$ & 11.7 & 13.5 & 10.8 \\
\hline Cellulose peak temperature $\left({ }^{\circ} \mathrm{C}\right)$ & 400 & 386 & 398 \\
\hline Cellulose maximum rate of mass loss $(\% / \mathrm{min})$ & 19.2 & 19.4 & 19.3 \\
\hline Lignin peak temperature $\left({ }^{\circ} \mathrm{C}\right)$ & 525 & ${ }^{\mathrm{a}}$ n.d & n.d \\
\hline Lignin maximum rate of mass loss $(\% / \mathrm{min})$ & 1.6 & n.d & n.d \\
\hline Residual mass fraction at $600^{\circ} \mathrm{C}$ & 0.24 & 0.23 & 0.23 \\
\hline
\end{tabular}

\footnotetext{
${ }^{\mathrm{a}}$ : Not determined.
} 
Table 16. Maximum rate of mass loss and peak temperature of major derivatives on the DTG curves of olive pomace samples.

\begin{tabular}{|c|c|c|c|c|c|c|c|c|}
\hline Sample identity & KT7 & KT12 & KT13 & KT23 & KT24 & KT25 & KT27 & КT32 \\
\hline Sample mass (mg) & 14.33 & 12.66 & 12.13 & 9.13 & 9.30 & 12.00 & 12.61 & 11.29 \\
\hline Sample moisture (\%) & 6.78 & 5.35 & 5.25 & 6.00 & 6.00 & 6.00 & 6.94 & 8.74 \\
\hline $\begin{array}{l}\text { Moisture peak } \\
\text { temperature }\left({ }^{\circ} \mathrm{C}\right)\end{array}$ & 80 & 82 & 80 & 74 & 68 & 80 & 89 & 88 \\
\hline Moisture maximum rate of mass loss (\%/min) & 1.3 & 1.8 & 1.5 & 2.0 & 1.5 & 1.2 & 2.2 & 2.1 \\
\hline $\begin{array}{l}\text { Hemicellulose peak } \\
\text { temperature }\left({ }^{\circ} \mathrm{C}\right)\end{array}$ & 318 & 315 & 316 & 273 & 312 & 319 & 328 & 286 \\
\hline $\begin{array}{l}\text { Hemicellulose maximum rate of mass loss } \\
(\% / \mathrm{min})\end{array}$ & 12.6 & 9.4 & 8.9 & 7.9 & 14.2 & 12.3 & 14.8 & 10.0 \\
\hline $\begin{array}{l}\text { Cellulose peak } \\
\text { temperature }\left({ }^{\circ} \mathrm{C}\right)\end{array}$ & 360 & 358 & 364 & 358 & 368 & 363 & 367 & 350 \\
\hline Cellulose maximum rate of mass loss (\%/min) & 14.4 & 14.0 & 15.3 & 10.5 & 18.1 & 13.8 & 13.1 & 14.7 \\
\hline $\begin{array}{l}\text { Lignin peak } \\
\text { temperature }\left({ }^{\circ} \mathrm{C}\right)\end{array}$ & ${ }^{\mathrm{a}}$ n.o. & n.o. & n.o. & n.o. & n.o. & n.o. & 486 & 500 \\
\hline Lignin maximum rate of mass loss (\%/min) & n.o. & n.o. & n.o. & n.o. & n.o. & n.o. & 3.9 & 4.1 \\
\hline Residual mass at $600^{\circ} \mathrm{C}$ & 0.29 & 0.30 & 0.31 & 0.25 & 0.28 & 0.23 & 0.17 & 0.07 \\
\hline
\end{tabular}

an.o.: not observed.

Table 17. Ranges and averages of DTG peak values and peak temperatures for moisture and lignocellulosic components of crude olive pomace.

\begin{tabular}{|c|c|c|}
\hline Parameter & Range & Average \\
\hline Moisture peak temperature $\left({ }^{\circ} \mathrm{C}\right)$ & $68-89$ & 80 \\
\hline Moisture ${ }^{\mathrm{a}} \mathrm{R} \max (\% / \min )$ & $1.3-2.2$ & 1.7 \\
\hline Hemicellulose peak temperature $\left({ }^{\circ} \mathrm{C}\right)$ & $273-328$ & 308 \\
\hline Hemicellulose R max (\%/min) & $7.9-14.8$ & 11.3 \\
\hline Cellulose peak temperature $\left({ }^{\circ} \mathrm{C}\right)$ & $350-368$ & 361 \\
\hline Cellulose R max (\%/min) & $10.5-18.1$ & 14.2 \\
\hline Residual mass fraction at $600\left({ }^{\circ} \mathrm{C}\right)$ & $0.07-0.31$ & 0.24 \\
\hline${ }^{\mathrm{b}}$ Residual mass fraction at $600\left({ }^{\circ} \mathrm{C}\right)$ & $0.17-0.31$ & 0.26 \\
\hline
\end{tabular}

a: Maximum rate of mass loss; ${ }^{\text {b }}$ : If residual mass fraction at $600^{\circ} \mathrm{C}$ for sample $\mathrm{KT} 32$ is excluded.

KT32 from the average residual mass fraction in Table 17, the value of the average for olive pomace is a little bit higher than that of wood samples.

\section{Conclusion}

When properly dried at the premises of olive mills, sun-dried crude olive pomace can be marketed with moisture content of $10 \%$ or less; therefore much of its heat content is densified. Removal of extractives by solvent extraction reduces the calorific value of crude olive pomace by a factor of about $10 \%$. Marketing crude olive pomace in loose or compact form has no significant effect on its gross calorific value. The loose form of crude olive pomace has about $21 \%$ of its mass in the form of grains with diameter $>2 \mathrm{~mm}$ and about $47 \%$ of fine particles of diameter $<0.5 \mathrm{~mm}$. The remaining $32 \%$ fall within the range of these size limits. These fractions have different calorific values. Although the calorific value of olive pomace is substantially lower than that of kerosene and diesel, its low market price and its abundance and renewability pave the way for its use as an affordable substitute for space heating in Jordan. Because of its scarcity and high prices, local fire wood cannot compete with olive pomace for space heating in Jordan. The crude olive pomace of Jordan is relatively rich in volatiles with 
mass percentage of $77.5 \%$. Because of their low moisture content and low nitrogen and sulfur contents, the net calorific values of the studied crude olive pomace samples amount to about $92 \%$ of their gross calorific values. The results of the TG and DTG measurements indicate the conformity of the pyrolysis of the lignocellulosic matter of the crude olive pomace samples to the pyrolysis behavior of other agrocellulosic biomass residues. The data on proximate and ultimate analyses as well as the calorimetric data can be reliably considered for specification purposes of olive pomace in Jordan.

\section{Acknowledgements}

The author is grateful to Yarmouk University for the financial support, to Mr. Eyad Hamzeh (JUST) for his assistance in the TG measurements, and to Miss Ayshyh Subeh (Yarmouk University) for her assistance in the extraction experiments and ash determination. Thanks are due to Professors M. Al-Khateeb, A. Al-Ajlouni, and E. Arafa (JUST) for their hospitability and for using their research equipment during my sabbatical leave.

\section{References}

[1] Al-Shdeifat, S.M. and Al-Bdoor, H.A. (2009) Annual Report. National Center for Scientific Research and Agricultural Extension, Jordan.

[2] Abu-Qudais, M. and Okasha, G. (1996) Diesel Fuel and Olive-Cake Slurry: Atomization and Combustion Performance. Applied Energy, 54, 315-326. http://dx.doi.org/10.1016/0306-2619(95)00077-1

[3] Al-Widyan, M.I., Tashtoush, G. and Khadair, A.I. (2002) Briquettes of Olive Cake as a Potential Source of Thermal Energy. Journal of Solid Waste Technology and Management, 28, 51-59.

[4] Jumah, R., Al-Kteimat, E., Al-Hamad, A. and Telfah, E. (2007) Constant and Intermittent Drying Characteristics of Olive Cake. Drying Technology, 25, 1421-1426. http://dx.doi.org/10.1080/07373930701536668

[5] Aljundi, I.H. and Jarrah, N.A. (2008) A Study of Characteristics of Activated Carbon Produced from Jordanian Olive Cake. Journal of Analytical and Applied Pyrolysis, 81, 33-36. http://dx.doi.org/10.1016/j.jaap.2007.07.006

[6] El-Sheikh, A.H., Sweileh, J.A. and Saleh, M.I. (2009) Partially Pyrolyzed Olive Pomace Sorbent of High Permeability for Pre-Concentration of Environmental Waters. Journal of Hazardous Materials, 169, 58-64.

http://dx.doi.org/10.1016/j.jhazmat.2009.03.061

[7] Tawarah, K.M. and Rababah, R.A. (2013) Characteristics of Some Jordanian Crude and Exhausted Olive Pomace Samples. Green and Sustainable Chemistry, 3, 146-162. http://dx.doi.org/10.4236/gsc.2013.34018

[8] Mata-Sánchez, J., Pérez-Jiménez, J.A., Díaz-Villanueva, M.J., Serrano, A., Núñez-Sánchez, N. and López-Giménez, F.J. (2014) Development of Olive Stone Quality System Based on Biofuel Energetic Parameters Study. Renewable Energy, 66, 251-256. http://dx.doi.org/10.1016/j.renene.2013.12.009

[9] Garcia-Maraver, A., Terron, L.C., Zambrano, M. and Ramos-Ridao, A.F. (2013) Thermal Events during the Combustion of Agricultural and Forestry Lopping Residues. In: Mendez-Vilas, A., Ed., Materials and Processes for Energy: Communicating Current Research and Technological Developments, Formatex, 407-411.

[10] Misra, M.K., Ragland, K.W. and Baker, A.J. (1993) Wood Ash Composition as a Function of Furnace Temperature. Biomass and Bioenergy, 4, 103-116. http://dx.doi.org/10.1016/0961-9534(93)90032-Y

[11] ASTM Standard D3172 (2007) Standard Practice for Proximate Analysis of Coal and Coke. ASTM International.

[12] Mayoral, M.C., Izquierdo, M.T., Andrés, J.M. and Rubio, B. (2001) Different Approaches to Proximate Analysis by Thermogravimetry Analysis. Thermochemica Acta, 370, 91-97. http://dx.doi.org/10.1016/S0040-6031(00)00789-9

[13] Cantrell, K.B., Martin II, J.H. and Kyoung, S.R. (2010) Application of Thermogravimetric Analysis for the Proximate Analysis of Livestock Wastes. Journal of ASTM International, 7, 1-13.

[14] Parikha, J., Channiwalab, S.A. and Ghosal, J.K. (2005) A Correlation for Calculating HHV from Proximate Analysis of Solid Fuels. Fuel, 84, 487-494. http://dx.doi.org/10.1016/j.fuel.2004.10.010

[15] Gaur, S. and Reed, T.B. (1998) Thermal Data for Natural and Synthetic Fuels. Marcel Dekker, New York, 259.

[16] Varol, M. (2006) Combustion and Co-Combustion of Olive Cake and Coalina Fluidized Bed. Thesis, Middle East Technical University, Ankara.

[17] Parr 587 M-6400 (2011) Oxygen Bomb Calorimeter Operating Instruction Manual. Chapter 7, Parr Instruments Company, Moline.

[18] ASTM Standard D5865-11A (2011) Standard Test Method for Gross Calorific Value of Coal and Cock. ASTM International, Appendix XI.

[19] Marsh, K.N. (1987) Recommended Reference Materials for the Realization of Physicochemical Properties. Blackwell, 
Oxford.

[20] Meraz, L., Dominguez, A., Kornhauser, I. and Roja, F. (2003) A Thermochemical Concept-Based Equation to Estimate Waste Combustion Enthalpy from Elemental Composition. Fuel, 82, 1499-1507. http://dx.doi.org/10.1016/S0016-2361(03)00075-9

[21] Brlek, T., Voca, N., Kricka, T., Levic, J., Vukmirovic, D. and Čolovic, R. (2012) Quality of Pelleted Olive Cake for Energy Generation. Agriculturae Conspectus Scientificus, 77, 31-35.

[22] Miranda, T., Esteban, A., Rojas, S., Montero, I. and Ruiz, A. (2008) Combustion Analysis of Different Olive Residues. International Journal of Molecular Science, 9, 512-525. http://dx.doi.org/10.3390/ijms9040512

[23] Integra Fuels. Typical Specifications of Olive Cake. http://www.integra-fuels.com/olive-cake-pellets.html

[24] Gravalos, I., Gialamas, T., Koutsofitis, Z., Kateris, D., Tsiropoulos, Z., Xyradakis, P. and Georgiades, A. (2008) Energetic Study on Animal Fats and Vegetable Oils Using Combustion Bomb Calorimeter. Journal of Agricultural Machinery Science, 4, 69-74.

[25] NIST Chemistry Web Book, NIST Standard Reference Database Number 69. http://www.en.wikipedia.org/wiki/Heat_of_combustion

[26] Heikkinen, J.M., Hordijk, J.C., de Jong, W. and Spliethoff, H. (2004) Thermogravimetry as a Tool to Classify Waste Components to Be Used for Energy Generation. Journal of Analytical and Applied Pyrolysis, 71, 883-900. http://dx.doi.org/10.1016/j.jaap.2003.12.001

[27] Sørum, L., Grønli, M.G. and Hustad, J.E. (2001) Pyrolysis Characteristics and Kinetics of Municipal Solid Wastes. Fuel, 80, 1217-1227. http://dx.doi.org/10.1016/S0016-2361(00)00218-0

[28] Wu, C.H., Chang, C.Y. and Lin, J.P. (1997) Pyrolysis Kinetics of Paper Mixtures in Municipal Solid Waste. Journal of Chemical Technology and Biotechnology, 68, 65-67. http://dx.doi.org/10.1002/(SICI)1097-4660(199701)68:1<65::AID-JCTB610>3.0.CO;2-T

[29] Yang, H., Yan, R., Chin, T., Liang, D.T., Chen, H. and Zheng, C. (2004) Thermogravimetric Analysis-Fourier Transform Infrared Analysis of Palm Oil Waste Pyrolysis. Energy \& Fuels, 18, 1814-1821. http://dx.doi.org/10.1021/ef030193m 
Scientific Research Publishing (SCIRP) is one of the largest Open Access journal publishers. It is currently publishing more than 200 open access, online, peer-reviewed journals covering a wide range of academic disciplines. SCIRP serves the worldwide academic communities and contributes to the progress and application of science with its publication.

Other selected journals from SCIRP are listed as below. Submit your manuscript to us via either submit@scirp.org or Online Submission Portal.
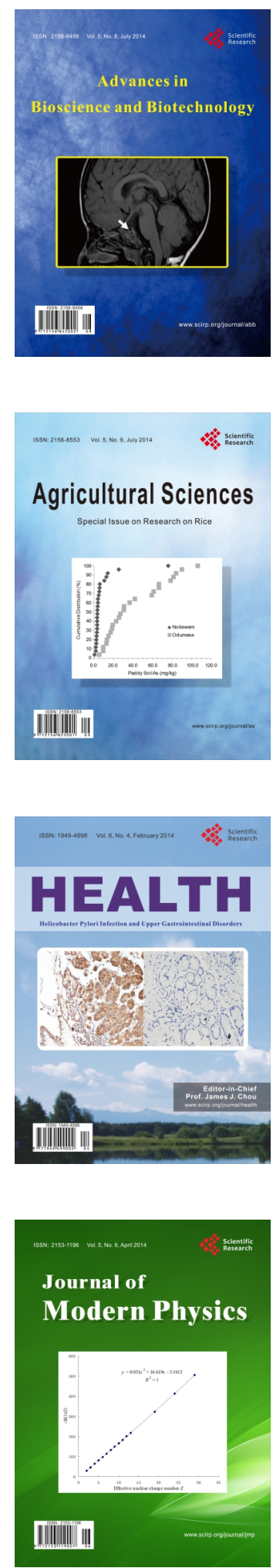
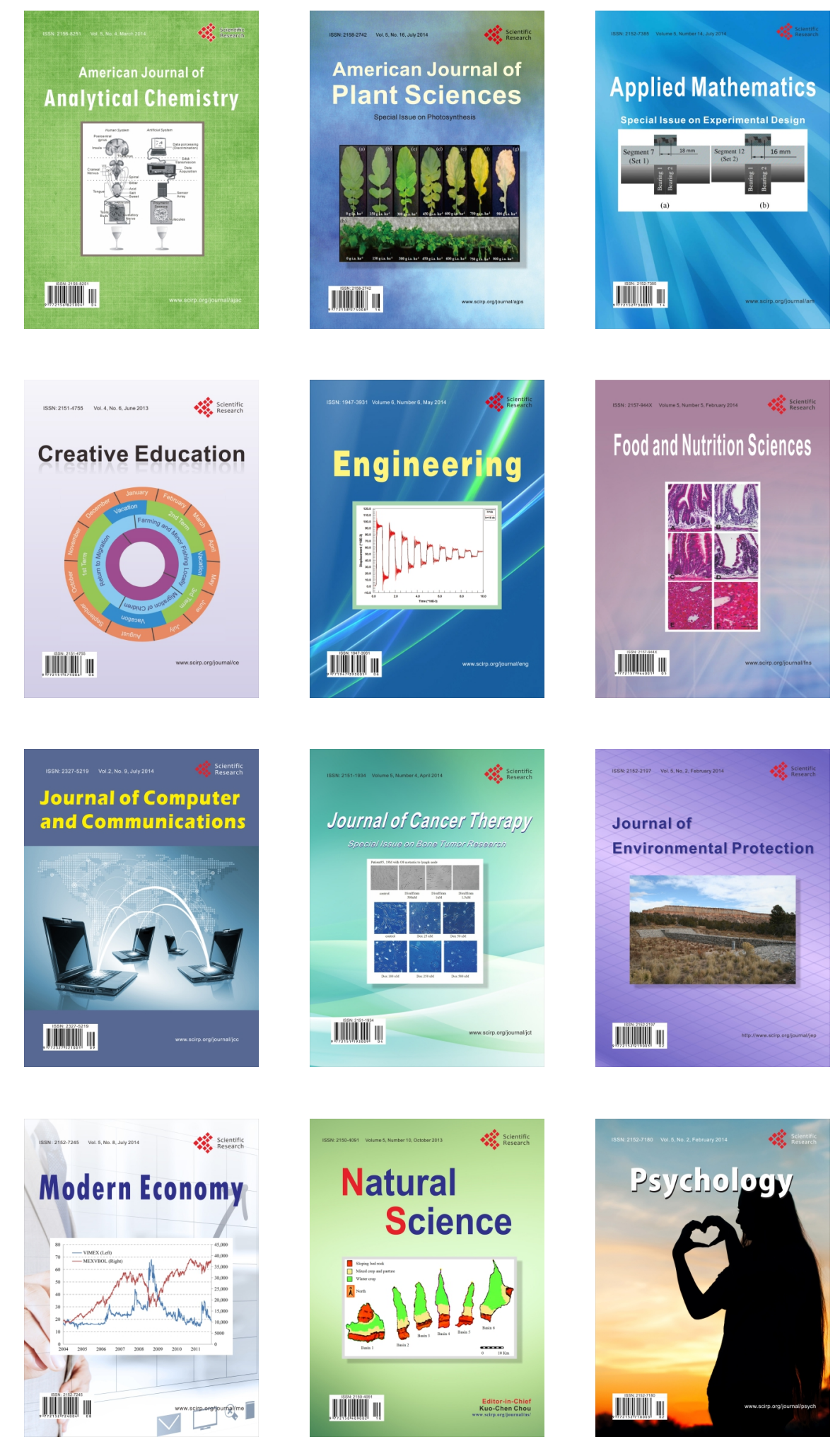